\title{
Formative evaluation on acceptance and usage of 'e-learning' platforms in developing countries: A case of Zimbabwe
}

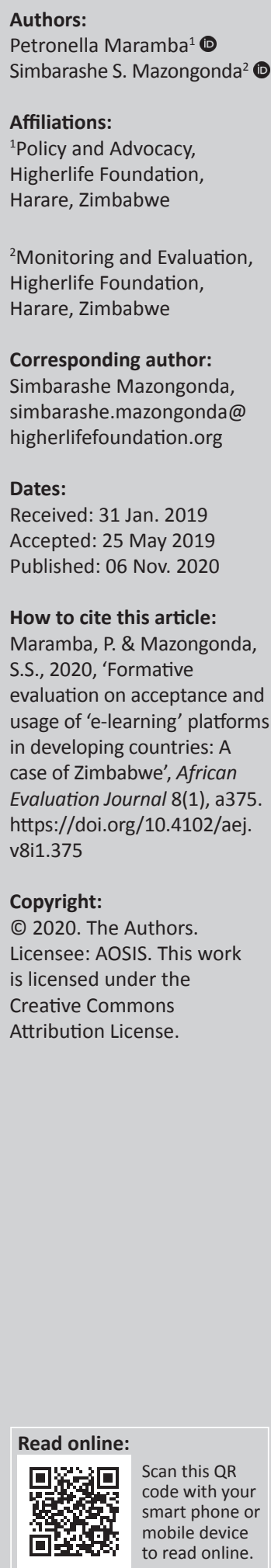

Background: The late uptake of technology in education in developing countries has necessitated this study through an evaluation on how Performance Expectancy (PE) and Facilitating Conditions (FC) influence teachers' behaviour on acceptance and usage of an e-learning platform called Ruzivo.

Objective: To investigate teachers' perceptions on the influence of their acceptance and use of the Ruzivo E-Learning Platform (RELP) through addressing the following key research questions: To what extent do teachers' perceptions of the use of the RELP enhance learning outcomes? What FC support teachers' use of the Platform?

Method: Based on the Unified Theory of Acceptance and Usage of Technology (UTAUT) model and its variants, a multiple-embedded case study based on both quantitative and qualitative research approaches was designed. Three primary schools participated in a questionnaire survey which captured the knowledge, perceptions and attitudes of teachers on PE and FC. Data on teachers experience with PE and FC was sought from a total of 18 teachers, (11 female and 7 male).

Results: The use of RELP has resulted in enhanced student learning outcomes and in the building of constructivist learning environments. Facilitating conditions such as the lack of adequate internet facilities, training and computer resources limit usage.

Conclusion: The content of Ruzivo should be revised to align with the demands of the updated curriculum, teachers need additional training on computer, and the project needs to be scaled up to realise the 'access to education' goal. Further, an accelerated adoption of e-learning platforms in institutions of learning is warranted.

Keywords: teachers' perceptions; performance expectancy; facilitating conditions; developing countries; Zimbabwe.

\section{Introduction}

This paper seeks to share the Zimbabwean experience regarding the acceptance and usage of 'e-learning' platforms in Zimbabwe. Since 1998, Zimbabwe, an example of a developing country, made traceable significant attempts to establish a knowledge-based society. This is evidenced by policy-driven studies to determine the appropriate course of action notably the Nziramasanga Education Commission (NEC) and the revision of the 1987 Education Act (Chapter 25:04). Other notable strides have been in the recent curriculum review which fosters 'e-leaning' platforms. In light of these interventions, it is worthwhile to explore whether the Government of Zimbabwe (GoZ) has achieved desired outcomes? One scholar vehemently argued that a solution to a challenge is best designed when the theory about its cause is well known and contextualised (Monaghan 2015). It is critical to note that Ruzivo was first introduced in 2015 by Higherlife Foundation to serve as an 'e-learning' platform that promotes access to quality education in Zimbabwe.

In this formative evaluation, we seek to answer the key question about the present situation in terms of existing conditions, resources and focus. This is more of a baseline study upon which future evaluative research would be premised. The main objective of this study is to investigate teachers' perceptions on the influence of their acceptance and use of the Ruzivo 'e-learning' platform in three primary schools in the Manicaland province of Zimbabwe. Derived from this main objective are the following sub-objectives: 
- To what extent do teachers' perceptions of the use of the Ruzivo 'E-Learning' platform enhance learning outcomes?

- What facilitating conditions support teachers' use of the platform? This position is inspired by Performance Expectancy (PE) and Facilitating Conditions (FC) vignettes of the Unified Theory of Acceptance and Usage of Technology (UTAUT).

We seek to combine UTAUT with an interpretive approach to allow for an in-depth understanding of the meanings given to these concepts in the Zimbabwean context. Details legitimising the selected platform and study areas under review are given in the methodology section.

\section{Background to the study}

Globally, there is a growing consensus that education, health and nutrition are the key variables in advancing the idea of human capital development for sustainable development (Penuel 2006; Selwyn 2011). Initiatives focusing on education by international agencies such as United Nations Children's Emergency Fund (UNICEF) have been at the fore in promoting access to quality education by all, particularly in developing countries. It has been argued that as early as 1980s and 1990s, governments shifted their attention towards improving students' learning outcomes (Downes, Perry \& Sherwood 1995; Penuel 2006; Selwyn 2011). Since 1996, 'e-learning' use has been increasing by $10 \%$ per year in the USA, Canada and some countries in Western Europe while simultaneously developing countries have been lagging behind. Australia, for instance, made the use of computers a required part of the education policy framework during 1990s (Downes et al. 1995). In terms of 'e-learning' initiatives, developed countries are a little advanced as compared to developing countries. This is partly attributed a number of obstacles such as restricted resources of professors and institutions measured both in time and financial terms (Zoroja, Skok \& Bach 2014).

\section{Theoretical framework}

To explain and improve on the appreciation of acceptance and usage of technology in education, this study leans on the UTAUT. The theory was developed by Venkatesh et al. (2003) after a thorough review and integration of eight dominant theories and models, namely: the Theory of Reasoned Action (TRA), the Technology Acceptance Model (TAM), the Motivational Model, the Theory of Planned Behaviour (TPB), a combined TBP/TAM, the Model of PC Utilisation, Innovation Diffusion Theory (IDT), and Social Cognitive Theory (SCT). These contributing theories and models have all been widely and successfully utilised by a large number of previous studies of technology or innovation adoption and diffusion within a range of disciplines including information systems, marketing, social psychology, and management. and it suggests that four core constructs (PE, effort expectancy [EE], social influence and FC) are direct determinants of behavioural intention and ultimately behaviour, and that these constructs are in turn moderated by gender, age, experience, and voluntariness of use (Venkatesh et al. 2003). It is argued that by examining the presence of each of these constructs in a 'real world' environment, researchers and practitioners will be able to assess an individual's intention to use a specific system, thus allowing for the identification of the key influences on acceptance in any given context.

\section{Analytical framework}

Deriving from the UTAUT Theory one can see that it is composed of four vignettes; 'Performance Expectancy (PE)', 'Effort Expectancy (EE)', 'Social Influence (SI)' and 'Facilitating Conditions (FC)'. The first three vignettes (PE, EE and $\mathrm{SI}$ ) impact directly and indirectly on user behaviour on technology user behaviour (Venkatesh et al. 2003). Performance expectancy relates to the teacher's perception of how the technology will enhance his or her job and student learning outcomes. Compared to the other variables, PE was found to be the strongest predictor of user behavioural intention. Effort expectancy refers to a user's perception of the ease of use of technology, and SI relates to individual's perception of general social forces to use (or not use) technology. Facilitating Conditions constitutes institutional and technical support in the form of resources, and other technical factors such as compatibility of the technology with other ICT gadgets. Facilitating Conditions directly impacts on the teacher's ability to use the system through availability of the relevant resources, skills and institutional and other support. Venkatesh et al. (2003) found four dependent constructs which have a moderating effect on the independent variables and these are gender, age, experience and voluntariness. Figure 1 is a schematic summary of the UTAUT which then forms the analytical framework for the study heavily influencing this study's design and methodological approach.

Unified Theory of Acceptance and Usage of Technology forms the subject of this section and sets the scene for forthcoming sections. Several sources concur that teachers play a crucial role in the process of integrating technology in the classroom (Bingimlas 2009; Gumusoglu \& Akay 2017; Hixon \& Buckenmeyer 2009; Ifenthaler \& Schweinbenz 2013). This realisation ignited researchers in education to make inquiries on how they can explain and predict teacher-technology adoption.

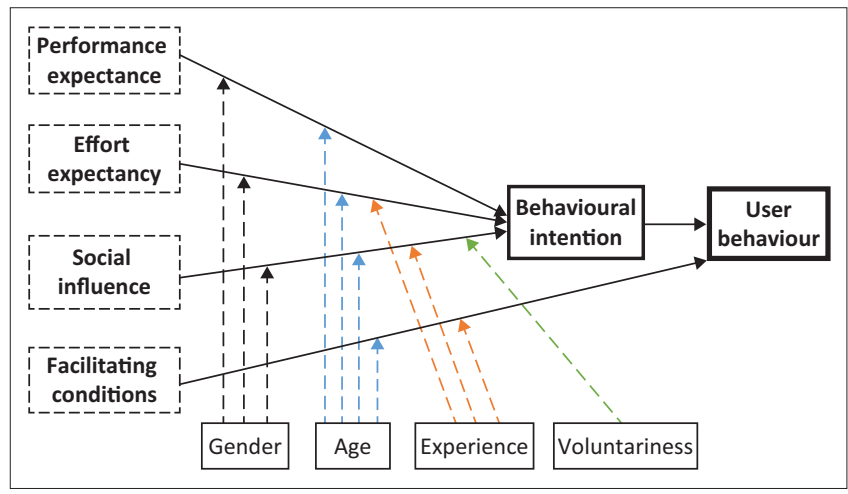

Source: Adapted from Venkatesh, V., Morris, M.G., Davis, G.B. \& Davis, F.D., 2003, 'User acceptance of information technology: Toward a unified view', Management Information Systems (MIS) Quarterly 27(3), 425-478. https://doi.org/10.2307/30036540

FIGURE 1: The Unified Theory of Acceptance and Usage of Technology model. 


\section{Brief literature on the theoretical perspectives on acceptance and usage of 'e-learning' platforms}

Although there may be useful similarities (and sharp contrasts too) in findings, researchers have over the years used different approaches to carry out their investigations as shown in Table 1.

\section{Premise of this study}

Zimbabwe is at a point where equipping the learner with 21st century skills is no longer just a matter of policy pronouncement, but of practice and urgency. Most accessible studies on usage and acceptance of technology demonstrated the importance of using technology to improve student learning outcomes (Chitanana 2009; Bukaliya \& Mubika 2011; Ertmer 1999; Majoni \& Majoni 2015; Mandoga, Matswetu \& Mhishi 2013; Sibanda, Mapenduka \& Furusa 2016). These studies have brought to light the critical role of teacher related factors such as the teachers' attitude towards technology, their educational beliefs, predominantly transmitter model, and external related factors such as the availability of computer and internet resources, and role of professional development courses in technology integration.

\section{Methodology}

This section gives details about the study area, research design, and ethical considerations, and data collection and analysis.

\section{Study area}

As alluded to earlier on, the study was conducted in purposefully selected districts of Manicaland Province in the eastern parts of Zimbabwe. Figure 2 shows the location of the province (in red) on the Map of Zimbabwe.

\section{Research design}

This study followed an explanatory embedded multiplecase study. Since the UTAUT model has several units within

\begin{tabular}{|c|c|c|}
\hline $\begin{array}{l}\text { Proponent } \\
\text { and Year }\end{array}$ & Proposition & Comment \\
\hline Perera (2011) & $\begin{array}{l}\text { Functional and } \\
\text { non-functional } \\
\text { requirements }\end{array}$ & $\begin{array}{l}\text { On the one hand, the former refers to the } \\
\text { services being provided. For example, strategies } \\
\text { for instruction to ensure cognitive development } \\
\text { and motivation of the child. On the other hand, } \\
\text { the latter includes the conditions that must be } \\
\text { met for the services to be effective, such as } \\
\text { provision of training and computer resources. }\end{array}$ \\
\hline Ertmer (1999) & $\begin{array}{l}\text { External/extrinsic/ } \\
\text { first order barriers } \\
\text { versus internal/ } \\
\text { intrinsic/second } \\
\text { order barriers }\end{array}$ & $\begin{array}{l}\text { External barriers are used to explain those } \\
\text { barriers outside the teacher's control and } \\
\text { internal barriers explain limiting factors that } \\
\text { the teacher can change on his or her own. }\end{array}$ \\
\hline $\begin{array}{l}\text { Balanskat, } \\
\text { Blamire, and } \\
\text { Kefala (2006) }\end{array}$ & $\begin{array}{l}\text { Micro, meso and } \\
\text { macro factors }\end{array}$ & $\begin{array}{l}\text { Micro factors relate to the teacher-centred } \\
\text { aspects, and meso factors are inclined to the } \\
\text { institution the teacher is working with, and } \\
\text { macro factors are associated with the wider } \\
\text { educational sector. }\end{array}$ \\
\hline
\end{tabular}

Note: The common strand in the above propositions is that they all recognise the central role of the teacher in technology integration in the education sector and the need to distinguish between barriers that a teacher has control over and can overcome on his or her own and others that only an external agency such as the government and/or the school can address. it that can be analysed, an explanatory embedded multiplecase study becomes appropriate. In an embedded design, subunits reside within the main unit (Yin 2009). As such, the main unit in this case study was Ruzivo 'e-learning' platform, whereas the subunits of analysis were explanatory variables drawn from the UTAUT that may explain the acceptance and usage of 'e-learning' platforms such as Ruzivo in schools.

\section{Research execution}

The study was designed as multiple-embedded case study. On one end, it is multiple because it was based on three intentionally selected primary schools that embraced Ruzivo platform between 2015 and 2017 in Manicaland, Zimbabwe. Initially, four primary schools were selected and later reduced to three schools because the fourth school is a middle-income school and relatively advanced in education technology use. These schools were purposively selected because they were some of the first schools to embrace Ruzivo following its introduction in 2015. On the other hand, it is embedded (focusing on two variable only) because it specifically focused on PE and FC variables of the UTAUT. The multipleembedded case study strategy enabled gathering of rich, detailed, and in-depth information characterising teachers who adopted Ruzivo.

This study adopted the mixed method research approach with a greater inclination towards qualitative approaches. In terms of sampling design, a total of 18 teachers were randomly selected from a list provided by the school heads to reflect key participants' characteristics such as gender, subject taught and student grade level. The teachers were told that participation in the survey was not compulsory, and their response names were not going to be disclosed with the view of protecting the identity of the respondents. Three Focus

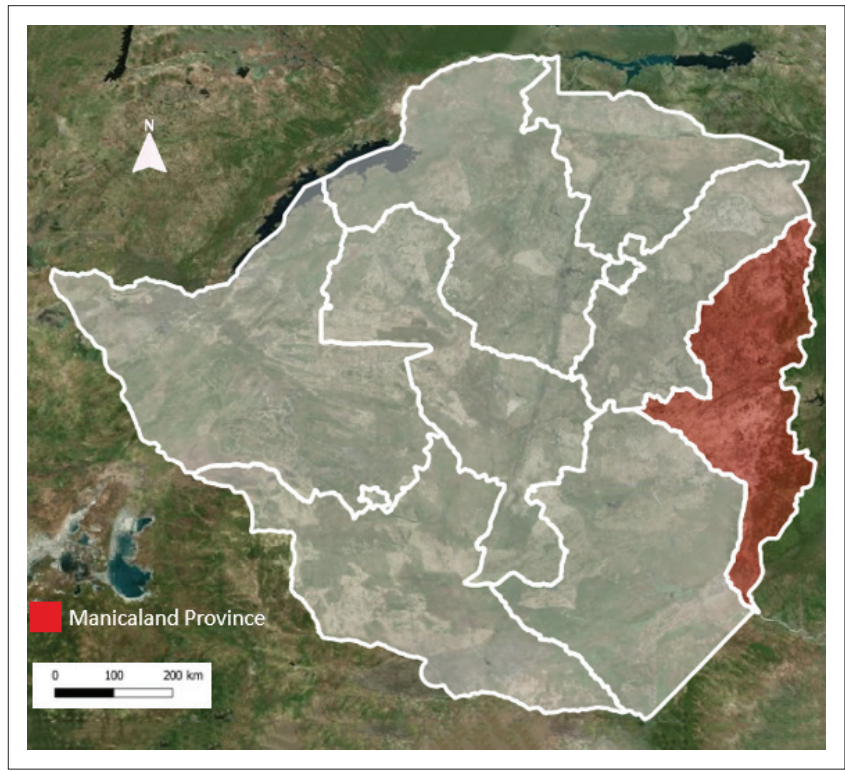

Source: https://en.wikipedia.org/wiki/Manicaland_Province FIGURE 2: Manicaland province in Zimbabwe. 
Group Discussions (FGDs), one per school, each composed of six teachers were conducted to solicit feelings, impressions and opinions of small groups of teachers regarding their challenges and experiences surrounding PE and FC.

After the selection of participants, a self-administered questionnaire based on a 1-5 Likert scale was structured using scenario-based questions meant to capture perceptions, attitude and knowledge of teachers on PE and FC. The questionnaire was composed of $28 \mathrm{PE}$ questions and $11 \mathrm{FC}$ questions. The questions were semi-structured to hew data relating the rationale behind specific responses. Follow-up and specifying questions were used to capture instrumental responses and noted to get deeper insights. Likert scale used in this study helped in calculating data profiles by generating measures of average and dispersion, and at the same time enabling ease of comparison of observations by teachers from different schools. Use of open-ended questions in FGDs allowed teachers to voice their feelings without being constrained by the researchers' perspective. Voice recorders were used to capture proceedings of FGDs and this ensured that all debates were recorded and no data was lost. Each FGD lasted for approximately 1 hour.

The analysis stage involved the entering and cleaning of quantitative data using SPSS software version 20. Qualitative data from the Likert Scales explanations and from the FGDs was examined separately through a process of transcription, coding and thematic analyses. Common themes were identified from the explanations under each question and used to explain the statistics for each question. Recordings were transcribed with the assistance of two research personnel. To ensure quality of analysis, we listened to each recording and cross checked them with the transcription.

\section{Ethical considerations}

In this study, the basics of ethics were respected which related to informed consent, privacy and confidentiality and accuracy. Permission was acquired from the Deputy Director-Junior Education [P5/MP/2018] from the Ministry of Primary and Secondary Education. With this permission we were able gain access into schools through District Education Officers. Informed consent required that research participants (teachers and students) had the right to be informed about the nature and consequences of the research they participate in. None of the participants was forced to participate; they agreed voluntarily based on full and open information. The researcher was honest about studying the usage of 'e-learning' platforms in schools, and this was clarified to teachers. Privacy and confidentiality insisted on safeguarding people's identities through the use of pseudo names where appropriate.

\section{Results and discussion}

This section presents and discusses the key findings from the data analyses. The first part of this section analyses socio-economic demographics of respondents to have a deeper understanding of the metrics characterising the respondents. This is followed by parts on PE and FC-related analyses regarding acceptance and usage of 'e-learning' platform. Throughout the analysis, reference will be made to existing theoretical, empirical and analytical issues in literature.

\section{Analysing the respondents' demographic characteristics}

Of the 18 teachers we interacted with, 11, constituting 61\%, were female and 7, constituting 39\%, were male. Female dominance can be explained by the fact that most primary school teachers are female. The difference is, however, insignificant because there is a marginal difference in mean PE by female and male teachers whose mean scores are 1.5 and 1.6 respectively. Viewing respondents through gender lenses reveals that a significant percentage of teachers who participated in the study have considerable experience since $83 \%$ of them are above 40 years of age. Figure $3 a$ is a scatter plot showing the age distribution of respondents and Figure $3 \mathrm{~b}$ shows usage of Ruzivo by teachers across subjects. Interestingly, Figure $3 b$ indicates that all the educators we interacted with are using Ruzivo, to some extent, for either teaching or lesson preparation and all of them intend to continue using the platform. Over $55 \%$ of teachers are using the platform in Mathematics and General paper. Usage is least in Art and Special classes (28\%) and there is an almost balanced distribution in usage and non-usage of Ruzivo learning platform in English, Shona and Agriculture.

Figure $3 a$ shows that there is no relationship between individual respondents and their ages because of nonexistence of a positive or negative relationship between the two variables. Essentially, ages of individual respondents did give a statistically meaningful pattern (either upward or downward). This implies that age is not a significant variable in understanding usage and acceptance of Ruzivo smart learning platform. Acceptance and usage of the platform is explained by other variables, other than age. Variables such as teachers' ICTs prior experience to using Ruzivo, access to ICT gadgets, and gender, arguably, are significant in acceptance and usage of 'e-learning' platforms. Finer details on usage of Ruzivo per any given teaching week were captured on a 1-5 plus scale following the revelation that all the research participants use Ruzivo to some extent. Results of the distribution of weekly frequency of usage the platform are shown in Figure 4. However, a few outlier cases have been noted that use the platform more than five times per week.

Interpreting the distribution in Figure 4, percentages have been used for ease of comparative assessment. Several teachers explained that they use Ruzivo, mainly for lesson preparation because the degree of usage is very high for once a week usage. As such, it can be logically deduced that it is mainly used as reference tool supporting the main reference source. The adage 'acceptance, is a gradual process and not an event' partly explains this. Teachers are used to their traditional hard 


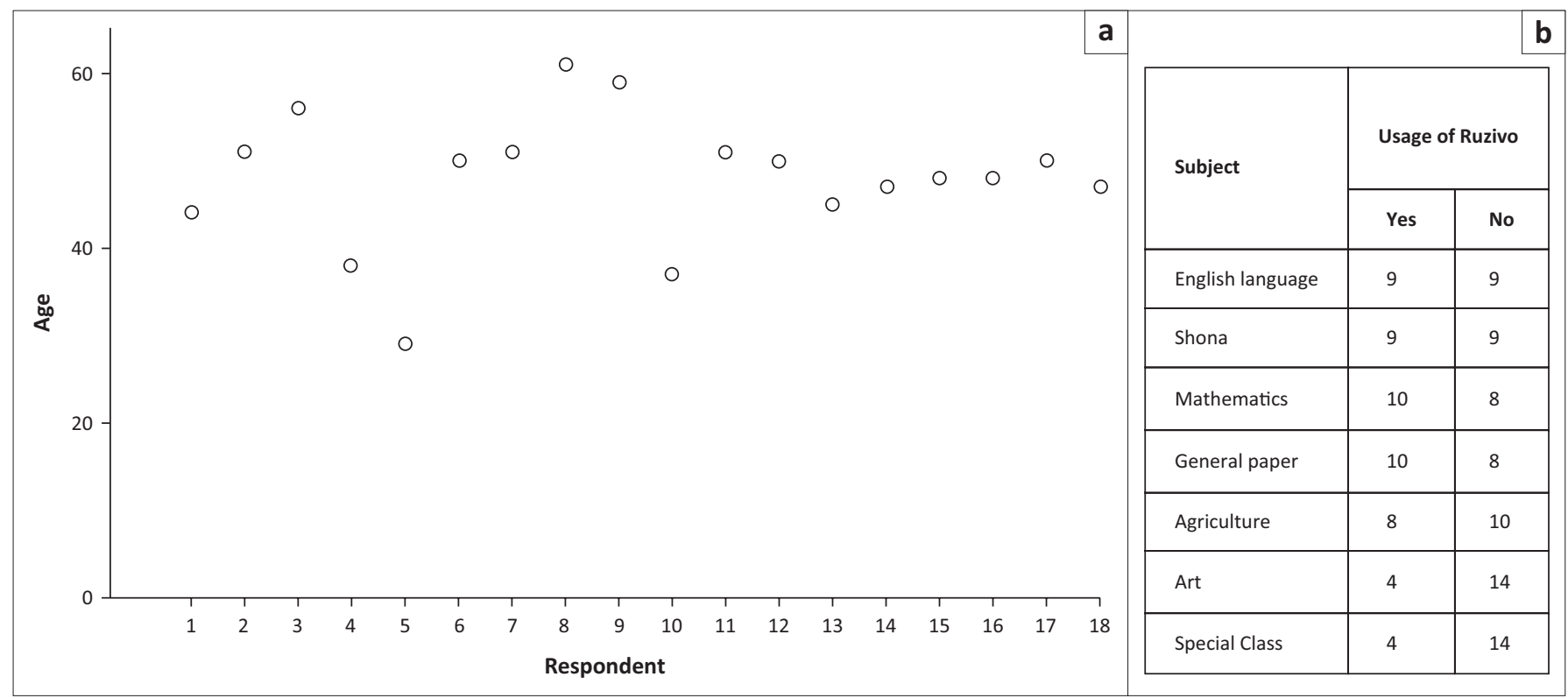

FIGURE 3: Age distribution of respondents and usage of Ruzivo across subjects. (a) Scatter plot showing age distribution of respondents. (b) Usage of Ruzivo across subjects.

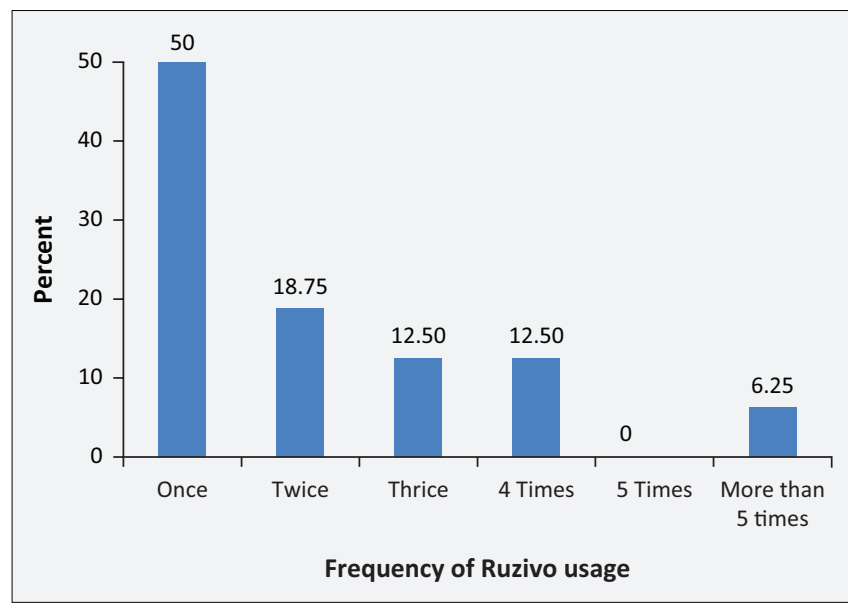

FIGURE 4: Percentage usage distribution.

copy based teaching methods. A probable explanation to the slow embrace of the importance of technology in lesson preparation, teaching and students' work assessment. An inquiry into driving and restraining forces behind usage further revealed that $25 \%$ of all users of Ruzivo use the platform once a week and have access to personal gadgets. This indicates a strong reliance on school-based computers and tablets to access Ruzivo and also a willingness on the part of the teachers to use the platform in spite of personal hindrances. However, frequency of usage among those with personal gadgets $(72.2 \%)$ is not that high as is evident from Figure 4 which is contrary to expectation that following trainings and encouragement by school heads, teachers would use the platform more regularly. Only $18.8 \%$ use it twice while equal numbers of $12.5 \%$ use it three and four times respectively.

\section{Performance expectancy}

This section analyses issues surrounding PE of teachers because of the incorporation of technology in their teaching methodologies. The general issues were captured using five

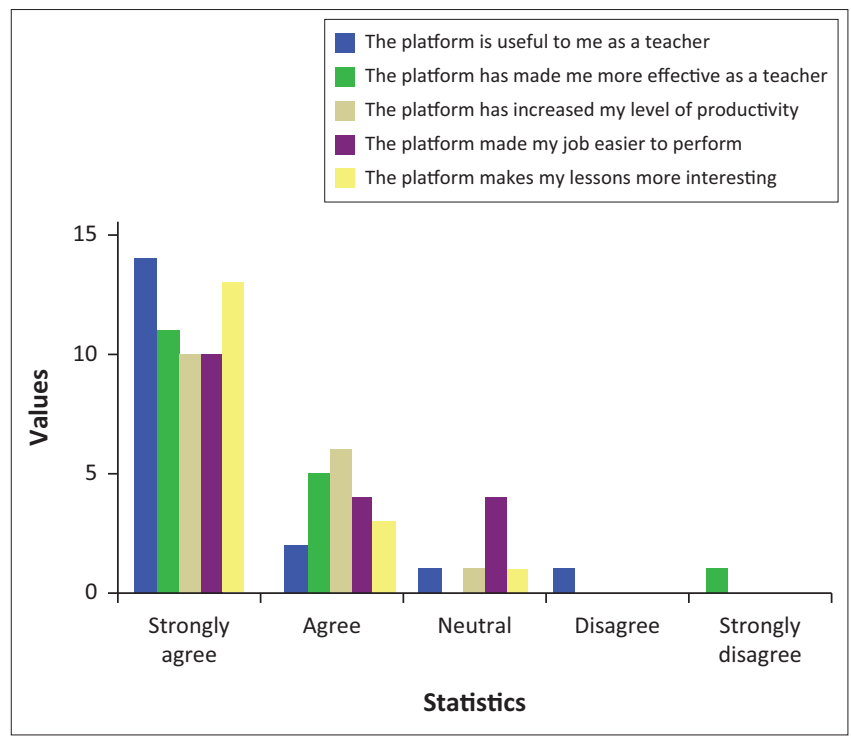

FIGURE 5: General issues on performance expectancy.

questions on usefulness, effectiveness, productivity, easiness, and engagement of the platform to the teachers' requirements. A lead-in summary of these general issues is summed up in Figure 5.

The majority of respondents generally found the digital learning platform useful to them, that it made their job easy and more effective, and more productive than before. Two major explanations to this reaction are the richness of the platform and syllabus-specific structure which makes it more relevant to the expected learning outcomes. Over and above that, the platform has been applauded for the incorporation of 'real pictures' in colour, thereby making lessons more interesting and also creating long-lasting impressions at the back of minds of learners. This alone increased student motivation and participation during lessons compared to before. On the same note, $11.1 \%$ of the respondents stated 
that the platform reduced the time a teacher spends with individual children allowing them to focus on slow learners.

However, the platform is not without drawbacks as explained by other teachers. Neutral responses on general questions reflect that some teachers are still indifferent whether there is a significant difference in used digital learning platforms and hardcopy-based platform. One instrumental response by an indifferent teacher is that the syllabus content is still the same but the packaging is different. Another instrumental response was given by a teacher who said the platform did not improve on effectiveness in as far as teaching is concerned. The key explanation to this instrumental response is that digital platforms have a number of pre-take off conditions such as the availability of electricity, adequate desktop computers or laptops or tablets, and availability of stable, reliable and smooth internet connectivity. Compared to the use of textbooks which do not need any such preconditions, it becomes less effective because it limits access for both teachers and students and the time they can spend on the platform. Further analysis on variables such as lesson preparation, teaching, monitoring students' progress, assignment of homework to learners, enhancement of teachers' skills, and positive contribution to cognitive development to learners was carried out.

The distribution of responses is positively skewed, indicating that the majority of responses are heavily loaded towards the positive side of the platform. There is a very little disagreement on the fact that the Ruzivo learning platform has improved teachers' experience in doing their work. The built-in mechanism for self-monitoring and monitoring by the teacher facilitates feedback to the student and to the teacher in real time. Responses relating to the provision of homework and student monitoring recorded the highest numbers of teachers who generally agreed with the Likert statements. An overwhelming $94.4 \%$ of the teachers either strongly agreed or agreed that the platform content is useful because it provides homework for children, and another $94.1 \%$ felt it is useful for monitoring students' progress and performance. Further to this, the teachers believe that the platform has the potential to promote student cognitive development because it facilitates independent learning through its level or age-specific syllabus-based content, diverse examples given in the lessons, exercises and tests with an immediate feedback mechanism. The greatest disagreement (including those that registered neutral) relates to whether the use of the platform is time-saving, which accounts for $42.9 \%$ of the disagreements. The most commonly cited reasons for these disagreements were related to the shortage of devices and inadequate technology for effective classroom delivery; the use of such technology should always be augmented with manual methods.

\section{Facilitating conditions}

Evidence from the FGDs has shown that all the teachers acknowledged overwhelming support being availed to them by school heads in ensuring that there is an enabling environment for them to use Ruzivo. Different themes came out of the FGDs excerpts, the first one had to do with the dedication and priority that has been given to access of 'e-learning' platforms by teachers. These themes include encouragement, infrastructural support and institutionalisation of 'e-learning' in some schools. To emphasise on this, one teacher had this to say:

'My school head has designed a time-table (for use of the platform) which should be followed by every teacher for the benefit of the children.' (Teacher A, female, school B)

Another pointer to the prioritisation of the Ruzivo 'e-learning' platform is given by one head who actually built a dedicated learning block for Ruzivo and other 'e-learning' platforms.

Though expressed differently, all the sentiments pointed out that school heads are providing material and moral support towards the adoption and use of Ruzivo. 94.3\% of the responses on this item indicated that the teachers are getting support from the school in using the platform. The form of school-based support cited includes encouragement and instilling of confidence by the school head, allocation of time on the time-table for each teacher to use the computer laboratory, provision of internet services, allocation of a specific computer laboratory where each teacher can take his or her class for a lesson, the presence of the ICT teacher as a hands-on helper and the provision of computers.

A significant percentage of teachers (88.9\%) revealed that additional support from Higherlife Foundation in the form of training, issuance of tablets and brand ambassadors seconded in schools to assist teachers proved helpful in facilitating the use of Ruzivo. Despite the availability of support in all its forms, $11.1 \%$ of the teachers revealed that there is a need for additional support for the objectives of incorporating ICT in education to see light of the day. Issues such as reliable internet connectivity, access to more ICT gadgets, and continuous training for teachers to develop confidence as some of them did not receive considerable training in computer literacy at teachers' college. The least cited factor among the facilitating conditions is full control of the platform. Issues of limited time to use computer laboratories and lack of adequate gadgets for use by both teachers and students rated high among the reasons given for lack of control over the use of the platform. This can be accounted for by the fact that only $27.8 \%$ of the participants do not have own personal gadgets they can use to access the platform.

\section{Discussion}

The positive feedback, on the acceptance and use of Ruzivo in Zimbabwe is supported by findings by Gumusoglu et al. (2017) which pointed out that ICTs in teaching increased the teachers' level of productivity. Pynoo et al. (2010) made similar conclusions from the data analysed from the survey questions. Regarding the influence of facilitating conditions on technology use noted in the present study, all the respondents in the study by Ifenthaler and 
Schweinbenz (2013) similarly noted the importance of technical infrastructure, for instance, for technology use and expected the school authorities to provide this. Overall, the importance of PE and FC noted and explained in the present study are supported by the main tenets of the UTAUTA, and numerous studies elsewhere, though in varying degrees (Balanskat et al. 2006; Gumusoglu et al. 2017). It must be noted that the present study was limited in sampling, and it was not holistic because it only studied two vignettes, PE and FC, of the UTAUT. In spite of these highlighted limitations, findings of this study are supported by existing empirical and theoretical literature.

\section{Conclusion and policy options}

Foregoing paragraphs collectively answered the question where are we now (in terms of the situation, conditions of existence, resources and focus). The study revealed that Zimbabwe, through the help of partners such as Highlife Foundation, has made positive attempts towards incorporating technology in education. Both PE and FC are at a satisfactory level which largely influenced behavioural intentions and user behaviour to embrace technology. However, there is a need to scale up such interventions and align the content with the updated curriculum following the adoption of the new curriculum by the GoZ. Most of the accessible content was developed in 2015 before the adoption of the updated curriculum. Furthermore, FC such as reliable internet connectivity and capacity building of teachers should be closely observed.

\section{Acknowledgements}

This paper is a culmination of the tireless, effervescent support we received from the following people: Jay Derrick who reviewed the paper and made several suggestions throughout the development process. School heads and teachers - We are indebted to the Headmasters and Teachers for their acceptance and willingness to share the success stories and challenges of the Ruzivo Digital Learning. Our Team Leader for Higherlife Foundation, Mrs Masiyiwa We are indebted to you for providing us the opportunity to learn. Your encouragement and unwavering support propelled us to do our best. Tobias Ngodzo - We are grateful for the on-the-ground facilitation with the relevant community stakeholders. Tatenda Mashanda and Nesbert Mushayanembwa - We are thankful to both of you for your assistance in the initial transcription of the qualitative data. Wiseman Teta - We greatly appreciate the valuable feedback you provided as we analysed the quantitative data. Joanna Masiyiwa - We are grateful for your assistance with the editing of the document.

\section{Competing interests}

The authors declare that they have no financial or personal relationships that may have inappropriately influenced them in writing this article.

\section{Authors' contributions}

P.M. mooted the idea of evaluating one of Higherlife Foundation's project. She framed the research and developed the manuscript; S.S.M. developed data collection tools, reviewed the manuscript, edited it.

\section{Funding information}

This research received no specific grant from any funding agency in the public, commercial or not-for-profit sectors.

\section{Data availability statement}

Data sharing is not applicable to this article as no new data were created or analysed in this study.

\section{Disclaimer}

The views expressed in this article are those of the authors and not an official position of the respective affiliated institutions.

\section{References}

Balanskat, A., Blamire, R. \& Kefala, S., 2006, The ICT Impact Report. A Review of Studies of ICT Impact on Schools in Europe', European Schoolnet/ European Commision, Brussels, viewed from 20 September 2018, from http://unpan1.un.org/intradoc/groups/public/documents/unpan/unpan037 334.pdf.

Bingimlas, K., 2009, 'Barriers to the successful integration of ICT in teaching and learning environments: A Review of the Literature', Eurasia Journal of Mathematics, Science and Technology Education 5(3), 235-245. https://doi.org/10.12973/ ejmste/75275

Bukaliya, R. \& Mubika, A.K., 2011, 'Teacher competence in ICT: Implications for computer education in Zimbabwean secondary schools', International Journal of Social Sciences and Education 4(1), 414-425.

Chitanana, L., 2009, 'An assessment of the utilisation of computers as teaching and learning resources: A case study of selected Gweru urban schools', Zimbabwe Journal of Educational Research 21(3), 323-339.

Downes, T., Perry, O. \& Sherwood, C., 1995, 'IT in education and education in Australia', Journal of Computer Assisted Learning 11, 23-34. https://doi.org/10.1111/j.1365 2729.1995.tb00111.x

Ertmer, P.A., 1999, 'Addressing first-and-second-order barriers to change: Strategies for technology integration', Educational Technology Research and Development 47(4), 47-61. https://doi.org/10.1007/BF02299597

Gumusoglu, E.K. \& Akay, E., 2017, 'Measuring technology acceptance level of teachers by using Unified Theory of Acceptance and Use of Technology', International Journal of Languages' Education and Teaching 5(4), 378-394. https://doi.org/ 10.18298/ijlet.2239

Hixon, E. \& Buckenmeyer, J., 2009, 'Revisiting technology integration in schools: Implications for professional development', Computers in the Schools 26(2), 130-146. https://doi.org/10.1080/07380560902906070

Ifenthaler, D. \& Schweinbenz, V., 2013, 'The acceptance of Tablet-PCs in classroom instruction: The teachers' perspectives', Computers in Human Behaviour 29(3), 525-534. https://doi.org/10.1016/j.chb.2012.11.004

Majoni, A. \& Majoni, C., 2015, 'Views of primary school teachers on the use of Information Communication Technology (ICT) in teaching and learning', Global Journal of Advanced Research 2(11), 1799-1806.

Mandoga, E., Matswetu, V. \& Mhishi, M., 2013, 'Challenges and opportunities in harnessing computer technology for teaching and learning: A case of five schools in Makoni East District', International Journal of Humanities and Social Science 3(1), 105-112.

Monaghan, T., 2015, 'A critical analysis of the literature theoretical perspectives on the theory-practice gap amongst qualified nurses within the United Kingdom', Nurse Education Today 35(8), e1-e7. https://doi.org/10.1016/j. nedt.2015.03.006

Penuel, W., 2006, 'Implementation and effects of one-to-one computing initiatives: A research synthesis', Journal of Research on Technology in Education 38(3), 329-348. https://doi.org/10.1080/15391523.2006.10782463

Perera, K.G.S.K., 2011, 'Model for integrating ICT in instructional process in Secondary Education: Sri Lankan perspective', SAARC Journal of Educational Research 8 , 73-111. 
Pynoo, B., Devolder, P., Tondeur, J., Van Braak, J., Duyck, W. \& Duyck, P., 2010 'Predicting secondary school teachers' acceptance and use of a digital learning environment: A cross-sectional study', Computers
568-575. https://doi.org/10.1016/j.chb.2010.10.005

Selwyn, N., 2011, Education and technology: Key issues and debates, Continuum, London.

Sibanda, M., Mapenduka, W. \& Furusa, S., 2016, 'Assessment of the availability and utilization of ICTs from teaching and learning in secondary schools: Case of a high school in Kwekwe, Zimbabwe', International Journal of Scientific and Technology Research 5(5), 282-288.
Venkatesh, V., Morris, M.G., Davis, G.B. \& Davis, F.D., 2003, 'User acceptance of information technology: Toward a unified view', Management Information Systems (MIS) Quarterly 27(3), 425-478. https://doi.org/10.2307/30036540

Yin, R.K., 2009, Case study research: Design and methods, 4th edn., Sage, Thousand Oaks.

Zoroja, J., Skok, M.M. \& Bach, M.P., 2014, 'E-Learning' implementation in developing countries: Perspectives and obstacles', in F.J. García Peñalvo \& A.M. Seoane Pardo (eds.), Online Tutor 2.0: Methodologies and Case Studies for Successful Learning, pp. 97-118, IGI Global, Hershey, PA. 